Thorax (1950), 5, 162.

\title{
THE BEHAVIOUR OF MIXTURES OF STREPTOMYCIN- SENSITIVE AND -RESISTANT TUBERCLE BACILLI IN LIQUID MEDIUM SENSITIVITY TESTS
}

\author{
BY \\ D. A. MITCHISON*
}

From the Department of Bacteriology, Postgraduate Medical School of London

A method for testing the sensitivity to streptomycin of strains of Mycobacterium tuberculosis has been recommended by the Streptomycin in Tuberculosis Trials Committee of the Medical Research Council (1948a). The tests are carried out in a modified Tween 80-albumen liquid medium (Dubos and Davis, 1946) containing various concentrations of streptomycin. It seems probable that strains derived from patients during or after treatment with streptomycin may consist of a mixture of organisms of different degrees of sensitivity (Pyle, 1947). An attempt has therefore been made to determine the proportion of resistant to sensitive organisms that could appear as resistant in the test. Since it has been shown that the presence of Tween 80 in the medium decreases the apparent concentration of streptomycin necessary to inhibit any particular strain (Fisher, 1948a and b; Williston and Youmans, 1949) media with and without Tween 80 have been used.

\section{METHOD}

The strains of $M$. tuberculosis used were of human type and were isolated from patients with pulmonary tuberculosis treated with streptomycin under the auspices of the Streptomycin in Tuberculosis Trials Committee of the Medical Research Council (1948b). Three pairs of strains were used. One of each pair was obtained from sputum before treatment started and the other after a period of treatment when strains isolated were showing resistance to streptomycin. The strains were first isolated on LöwensteinJensen medium and were then maintained on Dorset egg slopes at room temperature in the dark over periods of about a year, or were dried by the gelatin-ascorb:c acid technique of Stamp (1947). Sensitivity tests after the period of storage were the same as when originally isolated.

For use in these experiments the strains were grown in Tween 80-albumen liquid medium containing, in the case of the resistant strains, a concentration of streptomycin just insufficient to inhibit growth. One of the resistant strains grew freely in 1,000 $\mu \mathrm{g}$. streptomycin per $\mathrm{ml}$. and was grown in medium containing this concentration. The purpose of this procedure was to remove any sensitive organisms present in the strain. Details of the strains used are given in Table I.

The medium employed was that described in the Medical Research Council's (1948a) recommendations. This contained Tween 80 , and the same medium but without Tween 80 was also used. Growth in the latter medium was subsurface but not dispersed.

*In receipt of a grant from the Medical Research Council. 
TABLE I

Details of Strains of $M$. tuberculosis Used

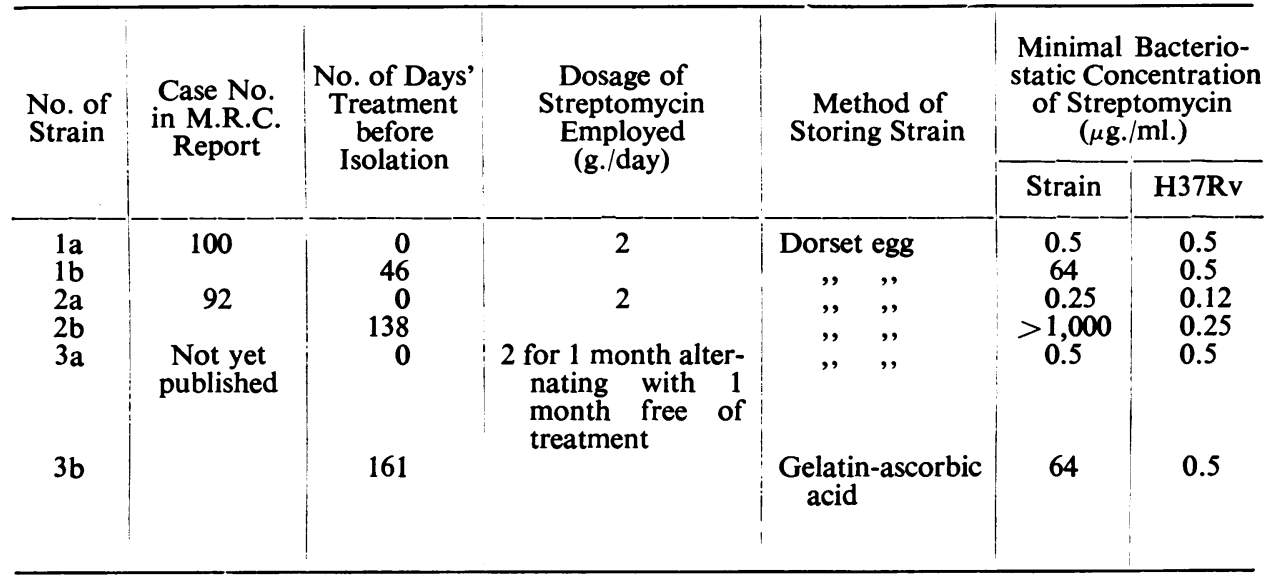

Volumes of $2.9 \mathrm{ml}$. of each type of medium containing streptomycin in concentrations of $0,0.12,0.25,0.5,1.0,10,100$, and $1,000 \mu \mathrm{g}$. per $\mathrm{ml}$. were then dispensed in $7 \mathrm{ml}$. screw-capped bottles.

Two flasks containing $50 \mathrm{ml}$. of Tween 80 -albumen medium were inoculated each with one of a pair of strains. These were incubated for $7-10$ days at $37^{\circ} \mathrm{C}$. The opacity of the growth was adjusted, if necessary, to correspond to Brown's No. 2 tube, and the dried weights of the bacilli per $\mathrm{ml}$. of medium were determined as an additional check that the same number of organisms were present in each suspension. Mixtures of the resistant and sensitive strains were then made in the series $1: 20,1: 40,1: 80$ $-1: 20,480$ resistant to sensitive, with, in one experiment, an extension to $1: 2 \times 10^{5}$ and $1: 2 \times 10^{6}$. Each of these mixtures was diluted $1: 5$, and $0.1 \mathrm{ml}$. quantities were added to a series of bottles containing medium with and without Tween 80 in the range of streptomycin concentrations described. Each experiment was set up in duplicate. The tubes were incubated at $37^{\circ} \mathrm{C}$. Readings were made every day from the fifth to the fourteenth days and also on the twenty-first, twenty-eighth, and thirty-fifth days. Uniform lighting conditions were employed and the presence or absence of growth noted.

\section{RESULTS}

The results of a typical experiment (strains $3 a$ and $3 b$ ) are as follows. In the medium containing Tween 80 the sensitive strain alone showed no growth in tubes containing $0.5 \mu \mathrm{g}$. streptomycin per ml. throughout the period of observation. The resistant strain alone showed no growth in tubes containing $100 \mu \mathrm{g}$. streptomycin per ml. up to the tenth day and in those containing $200 \mu \mathrm{g}$. per ml. up to the fourteenth day. From then onwards growth became apparent irregularly in bottles up to and including that containing $1,000 \mu \mathrm{g}$. per $\mathrm{ml}$. Since it had been grown previously in tubes containing $32 \mu \mathrm{g}$. streptomycin per ml. the resistant strain could be considered to be composed of organisms all of which were capable of growth in 10,1 , and $0.5 \mu \mathrm{g}$. per ml. Since the number of resistant organisms in successive 


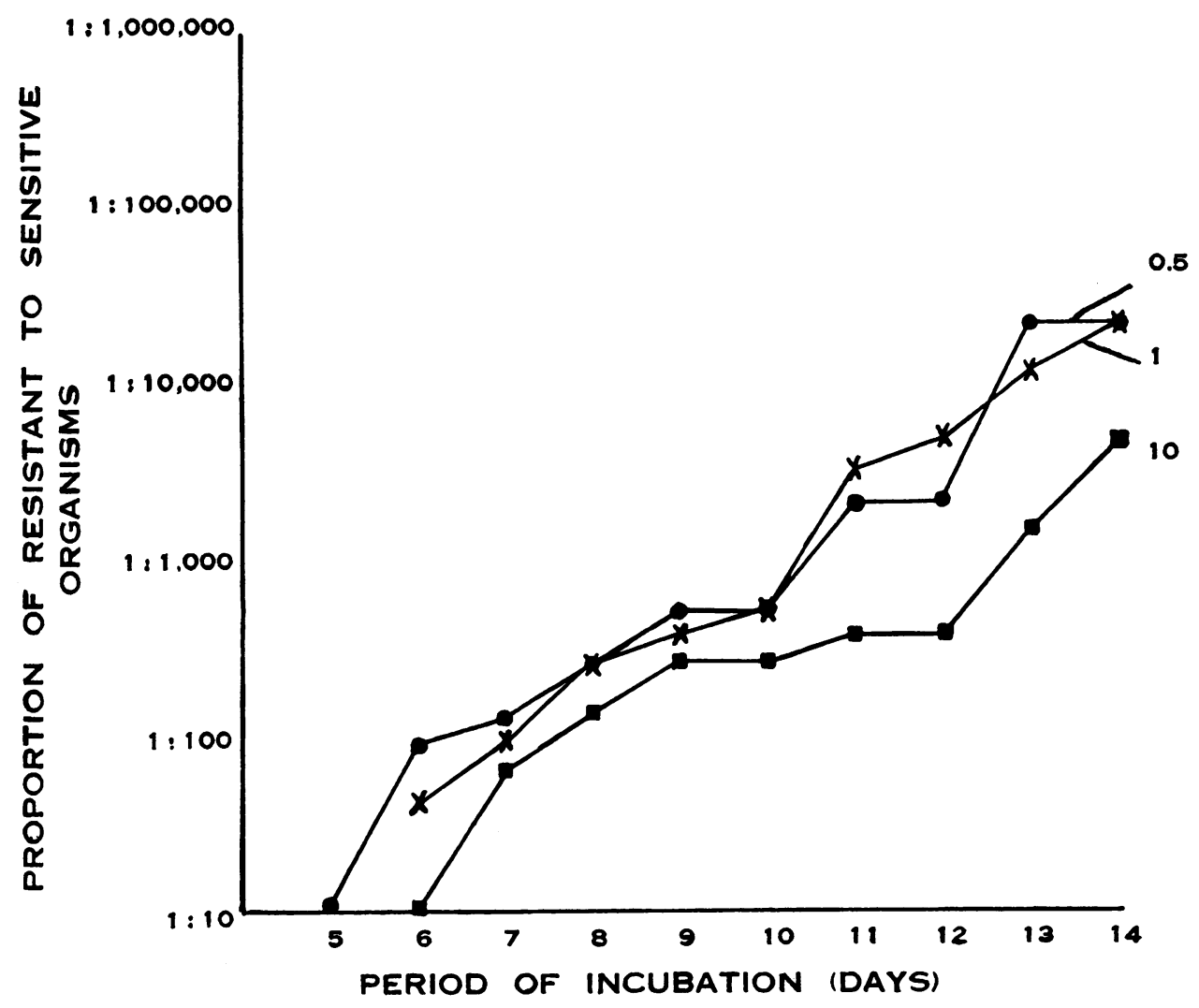

FIG. 1.-Proportions of resistant to sensitive organisms capable of causing visible growth after various periods of incubation in medium containing Tween 80 (strains $3 \mathrm{a}$ and $3 \mathrm{~b}$ ) and 10, 1 , and $0.5 \mu \mathrm{g}$. streptomycin per $\mathrm{ml}$.

pairs of tubes had been diluted by twofold steps an estimate of the limiting proportion of resistant to sensitive organisms which would give rise to growth in these intermediate concentrations could be made by using the table of Fisher and Yates (1948) for the densities of organisms estimated by the dilution method. These proportions are plotted against days of incubation in Fig. 1. As incubation is continued a smaller and smaller proportion of resistant organisms will cause visible growth in any one streptomycin concentration. The proportions of resistant to sensitive organisms capable of causing growth are the same for streptomycin concentrations of 0.5 and $1.0 \mu \mathrm{g}$. per ml., but are smaller for $10 \mu \mathrm{g}$. per ml.

In the medium without Tween 80 the sensitive strain was inhibited by $1.0 \mu \mathrm{g}$. streptomycin per $\mathrm{ml}$. throughout the period of observation. The resistant strain was inhibited by $200 \mu \mathrm{g}$. streptomycin per ml. up to the seventh day, but was capable of growth in $100 \mu \mathrm{g}$. per ml. (the highest concentration used) from the eighth day onwards. The limiting proportions of resistant to sensitive organisms causing growth are plotted against days of incubation in Fig. 2 for tubes containing streptomycin concentrations of $1.0,10$, and $100 \mu \mathrm{g}$. per ml. Here again, as incubation is con- 


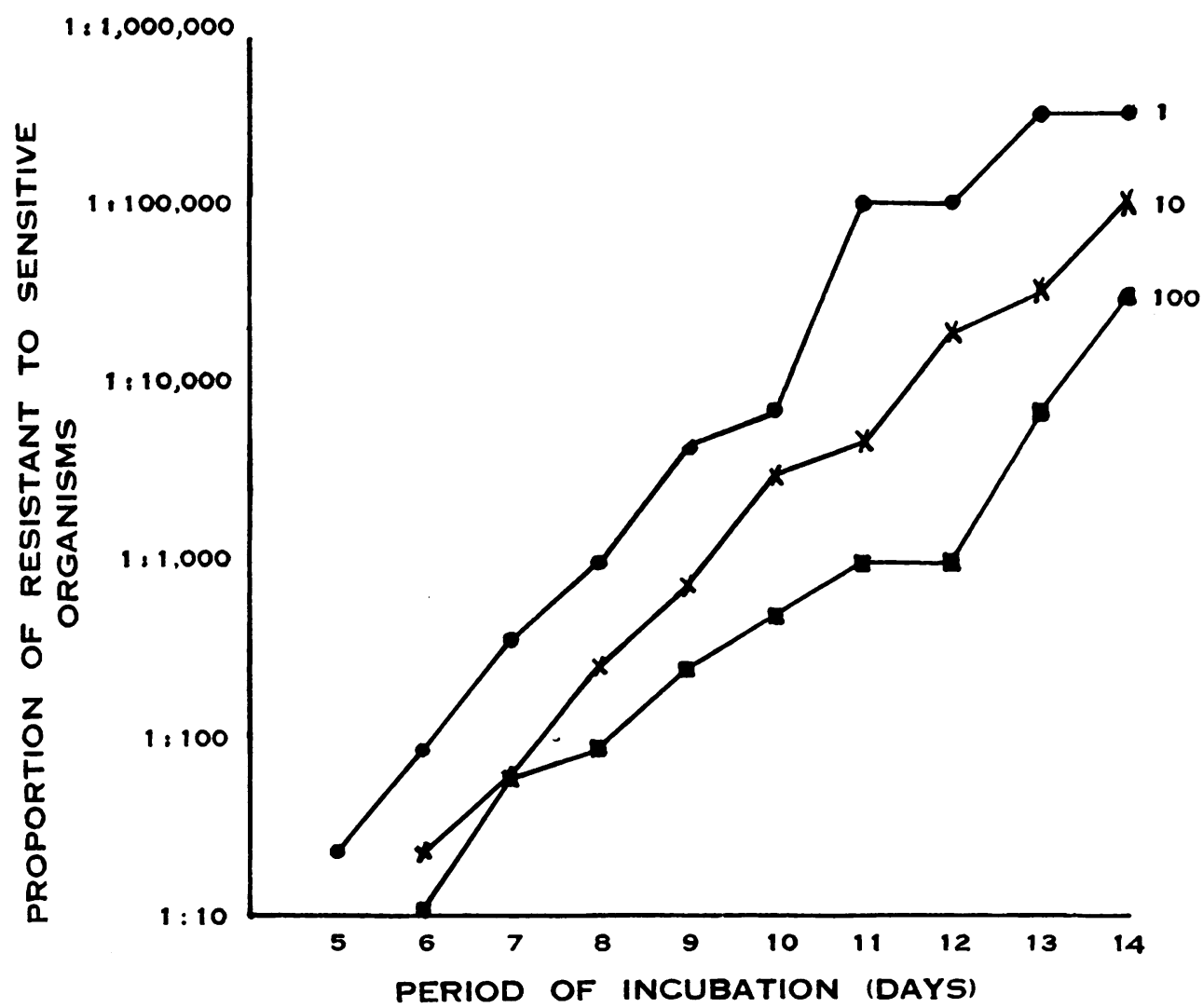

FIG. 2.-Proportions of resistant to sensitive organisms capable of causing visible growth after various periods of incubation in medium without Tween 80 (strains $3 a$ and $3 b$ ) containing 100, 10 , and $1 \mu \mathrm{g}$. streptomycin per $\mathrm{ml}$.

tinued the proportion of resistant organisms that will cause growth becomes smaller. Furthermore, at any day the proportion is smaller in the tubes containing $1.0 \mu \mathrm{g}$. streptomycin per ml. than it is in the tubes containing $10 \mu \mathrm{g}$. per ml. and this again is smaller than it is in the tubes containing $100 \mu \mathrm{g}$. per ml.

Straight lines were fitted to each series of points in Figs. 1 and 2 by the method of least square. The limiting proportions at 7,10 , and 14 days' incubation taken from these lines are given in Table II. The slope of these lines is a measure of the growth rate at the particular streptomycin concentration (Youmans and Youmans, 1949). As can be seen from Table II the growth rates in the medium with Tween 80 are less than in the medium without Tween 80 . Furthermore it seems probable that in either medium the growth rate is slower in concentrations of streptomycin just below that necessary to inhibit the growth of the resistant strain than it is at lower concentrations which are still capable of inhibiting the sensitive strain. Thus in the medium without Tween 80 the slopes of the lines for streptomycin concentrations of 1.0 and $10 \mu \mathrm{g}$. per ml. are steeper than that for $100 \mu \mathrm{g}$. per ml. Examination 
TABLE II

Proportions of Resistant to Sensitive Organisms Causing a Strain to Appear RESISTANT

\begin{tabular}{|c|c|c|c|c|c|c|c|}
\hline \multirow[t]{2}{*}{ Strain } & \multirow[t]{2}{*}{ Medium } & \multirow{2}{*}{$\begin{array}{c}\text { Concentration } \\
\text { of } \\
\text { Streptomycin } \\
(\mu \mathrm{g} . / \mathrm{ml} .)\end{array}$} & \multirow{2}{*}{$\begin{array}{l}\text { Rate of } \\
\text { Growth* }\end{array}$} & \multirow{2}{*}{$\begin{array}{l}\text { S.E. of } \\
\text { Rate of } \\
\text { Growth }\end{array}$} & \multicolumn{3}{|c|}{$\begin{array}{l}\text { Limiting Proportion of Resistant to } \\
\text { Sensitive Organisms after Period of } \\
\text { Incubation (Days) }\end{array}$} \\
\hline & & & & & 7 & 10 & 14 \\
\hline $\begin{array}{c}1 \mathrm{a} \\
\text { and } \\
1 \mathrm{~b}\end{array}$ & $\begin{array}{l}\mathrm{T} \\
\mathrm{T} \\
\mathrm{T} \\
\mathrm{NT} \\
\mathrm{NT}\end{array}$ & $\begin{array}{c}0.5 \\
1.0 \\
10 \\
1.0 \\
10\end{array}$ & $\begin{array}{l}0.310 \\
0.324 \\
0.267 \\
0.300 \\
0.305\end{array}$ & $\begin{array}{l}0.046 \\
0.040 \\
0.022 \\
0.017 \\
0.056\end{array}$ & $\begin{array}{l}1: 210 \\
1: 130 \\
1: 6 \\
1: 180 \\
1: 93\end{array}$ & $\begin{array}{l}1: 1,800 \\
1: 1,200 \\
1: 37 \\
1: 1,400 \\
1: 770\end{array}$ & $\begin{array}{l}1: 31,000 \\
1: 24,000 \\
1: 440 \\
1: 22,000 \\
1: 13,000\end{array}$ \\
\hline $\begin{array}{c}2 \mathrm{a} \\
\text { and } \\
2 \mathrm{~b}\end{array}$ & $\begin{array}{l}\text { T } \\
\text { T } \\
\text { T } \\
\text { NT } \\
\text { NT } \\
\text { NT } \\
\text { NT }\end{array}$ & $\begin{array}{c}10 \\
100 \\
1,000 \\
1.0 \\
10 \\
100 \\
1,000\end{array}$ & $\begin{array}{l}0.454 \\
0.446 \\
0.434 \\
0.866 \\
0.628 \\
0.619 \\
0.540\end{array}$ & $\begin{array}{l}0.016 \\
0.019 \\
0.048 \\
0.055 \\
0.068 \\
0.030\end{array}$ & $\begin{array}{ll}1: & 130 \\
1 & : 83 \\
1 & : 53 \\
1 & : 360 \\
1 & : 180 \\
1 & : 120 \\
1 & : 73\end{array}$ & $\begin{array}{ll}1: 2,700 \\
1: & 1,800 \\
1: & 1,100 \\
1 & : 140,000 \\
1 & : 13,000 \\
1 & : 9,000 \\
1: & 3,000\end{array}$ & $\begin{array}{l}1: 180,000 \\
1: 110,000 \\
1: 58,000 \\
1: 4,400,000 \\
1: 2,700,000 \\
1: 440,000\end{array}$ \\
\hline $\begin{array}{c}3 \mathrm{a} \\
\text { and } \\
3 \mathrm{~b}\end{array}$ & $\begin{array}{l}\text { T } \\
T \\
\text { T } \\
\text { NT } \\
\text { NT } \\
\text { NT }\end{array}$ & $\begin{array}{c}0.5 \\
1.0 \\
10 \\
1 \\
10 \\
100\end{array}$ & $\begin{array}{l}0.335 \\
0.345 \\
0.264 \\
0.496 \\
0.462 \\
0.384\end{array}$ & $\begin{array}{l}0.027 \\
0.017 \\
0.032 \\
0.030 \\
0.014 \\
0.030\end{array}$ & $\begin{array}{l}1: 97 \\
1: 88 \\
1: 42 \\
1: 340 \\
1: 79 \\
1: 36\end{array}$ & $\begin{array}{l}1: 980 \\
1: 950 \\
1: 260 \\
1: 11,000 \\
1: 1,900 \\
1: 510\end{array}$ & $\begin{array}{l}1: 21,000 \\
1: 23,000 \\
1: 3,000 \\
1: 1,000,000 \\
1: 140,000 \\
1: 17,000\end{array}$ \\
\hline
\end{tabular}

* The " rate of growth" is the slope of the line relating the log of the proportion of resistant to sensitive organisms to the number of days of incubation at which growth became apparent. $T=M e d i u m$ containing $T w e e n 80$. NT $=$ Medium without Tween 80 .

of the tubes at 21,28 , and 35 days provided a few further points on some of the lines.

Comparative data for the experiments with strains $1 \mathrm{a}, 1 \mathrm{~b}$ and $2 \mathrm{a}, 2 \mathrm{~b}$ are also given in Table II. Strain 1a (sensitive) was inhibited by $0.5 \mu \mathrm{g}$. streptomycin per ml. in medium with Tween 80 and by $1 \mu \mathrm{g}$. per ml. in medium without Tween 80 . Strain $1 \mathrm{~b}$ (resistant) was inhibited by $100 \mu \mathrm{g}$. streptomycin per ml. in medium with Tween 80 up to the fourteenth day and by $1,000 \mu \mathrm{g}$. per ml. up to the thirty-fifth day. In medium without Tween 80 it was inhibited by $200 \mu \mathrm{g}$. per ml. up to the thirteenth day, and grew in $1,000 \mu \mathrm{g}$. per $\mathrm{ml}$. from the twenty-first day onwards. Strain $2 \mathrm{a}$ (sensitive) was inhibited by $0.5 \mu \mathrm{g}$. streptomycin per ml. in medium with Tween 80 and by $1 \mu \mathrm{g}$. per ml. in medium without Tween 80 . Strain $2 \mathrm{~b}$ (resistant) grew freely in $1,000 \mu \mathrm{g}$. per ml. in media with and without Tween 80 . Similar results with these strains were obtained, but it will be seen that the growth rates differ considerably and, therefore, the limiting proportions of resistant to sensitive organisms capable of causing mixtures to appear resistant varies from experiment to experiment. With strains $2 \mathrm{a}$ and $2 \mathrm{~b}$ there was no significant difference between the rates of growth in medium with Tween 80 and without Tween 80. A separate batch of the basic medium was made up for each experiment so that it is possible that this variation might have been due to slight alterations in the medium or to differences between pairs of strains. 


\section{Discussion}

The bacteriologist who estimates the sensitivity of a strain of tubercle bacilli to streptomycin may be asked the question, What proportion of resistant to sensitive organisms in the strain will lead to its being classified as resistant ? The answer to this question depends on the period of incubation before the test is read. If the medium containing Tween 80 is used, and we ignore those concentrations of streptomycin just above the level which inhibits the sensitive strain, then after incubation for seven days these experiments indicate that the proportion varies between $1: 6$ and $1: 130$. After incubation for 10 days it varies between $1: 37$ and $1: 2,700$, and after 14 days between $1: 440$ and $1: 180,000$. Whether it is advisable to read the test after a short or a long period of incubation depends on the type of information required from the test, but the most information is obtained if tests are read after two or three periods of incubation. In practice I read sensitivity tests after 7,10 , and 14 days' incubation, using the 10 day observation as the one to be reported. With the majority of resistant strains end-points are the same at each reading, indicating that the strain is relatively homogeneous. Occasionally the first strain or two from a patient beginning to produce resistant organisms will give an endpoint at a much higher streptomycin concentration at the fourteenth day reading than at the seventh, indicating that the strain contains only a small proportion of resistant bacilli.

A similar experiment to these has been reported by Wolinsky, Reginster, and Steenken (1948). In medium containing Tween 80 and streptomycin they found that $20 \%$ resistant organisms in the inoculum initiated growth in 7 days, $1 \%$ in 11 to 12 days, $0.1 \%$ in 14 to 16 days, and $0.01 \%$ in 17 to 19 days. These results indicate a lower proportion of resistant to sensitive organisms capable of causing growth after any given period of time than in the experiments reported in this paper, but the medium used and various details of the procedure were slightly different. Furthermore their results were the same in media with and without Tween 80 , which differs from the results obtained with two of the pairs of strains used in this paper. Experiments on the growth rate of tubercle bacilli in medium with and without Tween 80 (Sattler and Youmans, 1948 ; Youmans and Youmans, 1949) indicate that it is slower in medium with Tween 80 . This adds weight to the assumption that the proportion of resistant to sensitive bacilli needs usually to be greater in media with Tween 80 than in those without it to cause growth in concentrations of streptomycin above those necessary to inhibit the sensitive strain. This assumption might at least partially explain the higher levels of streptomycin found necessary to inhibit strains of tubercle bacilli in media without Tween 80 than in media with it (Williston and Youmans, 1949 ; Fisher 1948a). This difference between media with and without Tween 80 is greatest when the sensitivity of resistant strains is measured, and these strains are likely to be less homogeneous in respect to streptomycin sensitivity than sensitive ones.

\section{SUMMARY}

The proportion of resistant to sensitive tubercle bacilli necessary to cause a streptomycin sensitivity test to be read as resistant has been determined in Tween 80 albumen liquid medium and in the same medium without Tween 80 . After seven 
days' incubation these proportions vary from $1: 6$ to $1: 130$. After 10 days' incubation they vary from $1: 37$ to $1: 2,700$, and after 14 days from $1: 440$ to $1: 180,000$. The growth rate of bacilli is greater in medium without Tween 80 than with it. This may partially account for differences in the streptomycin sensitivity of strains measured in the two media.

Thanks are due to Miss M. L. Girvan for technical assistance.

\section{REFERENCES}

Dubos, R. J., and Davis, B. D. (1946). J. exp. Med., 83, 409.

Fisher, M. W. (1948a). Amer. Rev. Tuberc., 57, 53.

(1948b). Ibid., 57, 58.

Fisher, R. A., and Yates, F. (1948). Statistical Table for Biological, Agricultural, and Medical Research, Table VIII, 3rd edition, p. 49. Oliver and Boyd. London.

Medical Research Council (1948a). Lancet, 2, 862. (1948b). Brit. med. J., 2, 769.

Pyle, M. M. (1947). Proc. Mayo Clin., 22, 465.

Sattler, T. H., and Youmans, G. P. (1948). J. Bact., 56, 235.

Stamp, Lord (1947). J. gen. Microbiol., 1, 257.

Williston, E. H., and Youmans, G. P. (1949). Amer. Rev. Tuberc., 59, 336.

Wolinsky, E., Reginster, A., and Steenken, W. (1948). Ibid., 58, 335.

Youmans, G. P., and Youmans, A. S. (1949). J. Bact., 58, 247. 